Other elements of the Plan have been covered through discussion exercises and workshops in the months leading up to the operational phase. These activities have addressed border control and screening, decision-making, deployment of the national medical stockpile and the national health emergency response. They have involved all states and territories, as well as Australian Government agencies.

Effective communication between participants and between participants and the public/front-line health providers is a particular focus of all elements of Cumpston 06. A final consolidated report will be prepared in early 2007 to disseminate the findings to policy makers and to enable future exercises to draw on the Cumpston 06 experience.

\section{CONCLUSION}

The Australian Government has set in train a wide range of initiatives to prepare the nation in the event of an influenza pandemic. Planning and plan testing, involving all levels of Government, are important parts of the work being done to limit the impact of any pandemic on the well being of Australians.

\section{REFERENCES}

1. Department of Health and Ageing. Australian health management plan for pandemic influenza. Canberra: Department of Health and Ageing, 2006.

2. Department of Health and Ageing. Interim national pandemic influenza clinical guidelines. Annex to Australian health management plan for pandemic influenza. Canberra: Department of Health and Ageing, 2006.

3. Department of Health and Ageing. Interim infection control guidelines for pandemic influenza in healthcare and community settings. Annex to Australian health management plan for pandemic influenza. Canberra: Department of Health and Ageing, 2006.

4. Becker N, Glass K, Barnes B, Caley P, Philp D, McCaw et al. Using mathematical models to assess responses to an outbreak of an emerged viral respiratory disease. Canberra, Australian Government Department of Health and Ageing: unpublished research paper, 2006. 암

\title{
PREPARING FOR THE NEXT INFLUENZA PANDEMIC: A NEW SOUTH WALES PERSPECTIVE
}

\section{Paul Armstrong}

Biopreparedness Unit

NSW Department of Health

\section{Kerry Chant \\ Centre for Health Protection \\ NSW Department of Health}

\section{ABSTRACT}

Pandemic influenza is one of a small number of infectious diseases that pose a significant global threat. Pandemic preparedness has accelerated around the world in recent years in response to the perceived increased risk of a pandemic developing following the emergence of $\mathrm{H} 5 \mathrm{~N} 1$ avian influenza in domestic poultry flocks in Asia, Africa and Europe. There is a hierarchy of pandemic plans international, national, state, and local - and harmonisation of all of these is imperative for a coordinated and effective response. At the national and state levels, plans have been developed for a whole-of-government response to a pandemic, in addition to plans specifically for the health sector. It is inevitable that influenza pandemics will occur and careful planning is crucial to mitigate their potentially devastating effects.

Pandemic influenza is one of a small number of infectious diseases that pose a significant global threat. This group of infectious diseases are characterised by a capacity to cause significant degrees of illness, death, economic loss, and public fear and panic. A convenient way of classifying them is as emerging, re-emerging, and deliberately emerging infectious diseases. ${ }^{1}$ Emerging infectious diseases are those that have never been recognised before, a recent example being severe acute respiratory syndrome (SARS). Influenza pandemics are an example of re-emerging infectious diseases, which are those that have been recognised for some time but undergo a resurgence in a different form or geographical location. Deliberately emerging diseases are those that are intentionally introduced and are synonymous with diseases caused by agents of bioterrorism.

These different types of infectious diseases are dealt with here as a group because there are many overlapping preparedness activities for each of them. ${ }^{1}$ Of these disease threats, influenza pandemics present the greatest potential risk in that, by their very nature, the entire population will be at risk at the same time and the virus spreads quickly. Should the pandemic influenza virus be highly virulent, as H1N1 was in 1918-1919, then large-scale deaths could result. SARS, by comparison, caused less than 0.1 per cent of the deaths that resulted from the mildest influenza pandemic of the last century. ${ }^{2,3}$ The magnitude of the threat to the public health posed by an influenza pandemic means that preparing adequately for such an event will go a long way towards preparing for all large-scale infectious disease threats.

\section{WHY DO WE NEED TO PREPARE?}

The world needs to prepare for the next influenza pandemic for two important reasons. First, a pandemic will occur at 
some stage in the future. History has shown us that influenza pandemics do occur periodically - approximately every 10 to 50 years, based on pandemics that have occurred over the past 300 years - and there is no reason to believe that they will not continue to occur. The influenza viruses that caused the past three pandemics - the Spanish influenza pandemic of 1918-1919, the Asian influenza pandemic of 1957-1958, and the Hong Kong influenza pandemic of 1968-1969 - all originated, either wholly or in part, from avian influenza strains. ${ }^{1,4}$ The risk of a pandemic influenza virus developing from the HN51 avian influenza strain causing the current epizootic in domestic and wild birds on three continents is unknown, but the sheer magnitude of the global viral load of $\mathrm{H} 5 \mathrm{~N} 1$ has many experts predicting that the current risk is at the highest level for several decades.

Second, although the severity of the next pandemic cannot be accurately predicted, the effects are potentially significant in terms of morbidity, mortality and disruption to the social fabric. By preparing for such events, these effects may be lessened.

\section{HIERARCHY OF INFLUENZA PANDEMIC PLANS FOR THE HEALTH SECTOR}

To ensure a coordinated and effective response to an influenza pandemic it is imperative that pandemic plans at all levels of governance-international, national, state, and local—work in harmony.

\section{International plans}

At the international level, leadership in global pandemic planning has been provided by the World Health Organization (WHO), which accelerated its preparedness activities in the wake of the 1997 H5N1 avian influenza outbreak in birds and humans in Hong Kong. The WHO produced its first global pandemic plan in 1999 and this was revised in 2005. ${ }^{5}$ In these plans, the WHO urged all countries to formulate their own pandemic plans.

The framework on which the WHO plans are based is the so-called "WHO pandemic global alert phases". To reflect the ongoing need for pandemic preparedness, the world is always in a defined phase. In recognition of the public health risk posed by avian influenza strains such as the H5N1 strain, these phases were redefined in the 2005 plan to give a greater emphasis to the public health response to avian influenza. Another important change in the 2005 plan was an acknowledgement that there may be a difference between the global alert level and the alert level in a particular country. At the time of writing in September 2006, the WHO pandemic alert level was at Overseas phase 3 (human infection with a new influenza subtype but only rare person-to-person transmission), and at Australia phase 0 (no animal influenza strains affecting humans). The final major change in the 2005 plan was factoring in the potential to contain or delay the spread of a new human influenza strain by a rapid, coordinated global and national response.

\section{National plans}

At the national level, the Australian Government has devoted significant resources to preparing for an influenza pandemic. Since 2003, more than $\$ 550$ million has been budgeted for vaccine development, stockpiling antiviral medications and essential medical equipment, enhancing regional preparedness, and funding accelerated research in pandemic influenza fields. ${ }^{6}$ In June 2005, the Australian Government Department of Health and Ageing released the Australian Management Plan for Pandemic Influenza (AMPPI). ${ }^{7}$ It adopted the concept of the WHO global pandemic phases and therefore is designed to be used at all times. The AMPPI outlines governance and decisionmaking arrangements, describes the 'building blocks' for pandemic planning, and sets out responses and roles and responsibilities for the various pandemic phases under five broad headings - planning and coordination, monitoring and surveillance, public health measures (non-pharmacological and pharmacological), health care and emergency response, and communications. A number of annexes provide a more detailed explanation of certain planning elements, and early guidelines for surveillance, laboratory, and infection control. In May 2006, a revised version of AMPPI was released, now entitled Australian Health Management Plan for Pandemic Influenza to differentiate it from nonhealth sector national pandemic plans, with three important annexes attached: Interim Infection Control Guidelines for Pandemic Influenza in Healthcare and Community Settings, Interim National Pandemic Influenza Clinical Guidelines, and Communications Strategy Overview. ${ }^{6}$

\section{NSW plan}

In November 2005, the NSW Health Interim Influenza Pandemic Action Plan ${ }^{8}$ was released. It was called an 'interim' plan in recognition of the rapid progression in pandemic planning and the likelihood that early planning strategies would change, and to indicate that it would be updated regularly. Like the national plan, the NSW plan is based around the WHO pandemic phases and outlines governance and decision-making arrangements, describes the key elements of pandemic planning, and sets out responses and roles and responsibilities for the various pandemic phases under the same five broad headings of the $A M P P I$ :

- planning and coordination involves the development and maintenance of state and local pandemic plans

- monitoring and surveillance calls for a number of complementary surveillance methods, including 'conventional' methods used for surveillance of seasonal human influenza as well as novel methods of influenza surveillance to be introduced in the later pandemic phases

- non-pharmacological public health measures include quarantining of individuals, towns or regions exposed to the pandemic virus, screening for influenzalike illnesses at borders, the use personal protective 
equipment, and closure of schools and non-essential workplaces to lessen the rate of spread of the virus

- pharmacological public health measures are mainly concerned with anti-influenza drugs and vaccines (seasonal influenza and pneumococcal vaccines in the interpandemic period, and pandemic influenza vaccines when a novel influenza strain emerges)

- health care and emergency response includes the testing of pandemic plans, development and implementation of infection control and clinical management guidelines, hospital capacity, designated influenza hospitals, fever clinics, areas for mass quarantine of individuals, monitoring of contacts of cases, and workforce issues

- communications involves the timely provision of accurate information to the public, the healthcare workforce, and other key stakeholders.

\section{Local plans}

Finally, at the local level, each area health service in NSW has completed a draft influenza pandemic plan, based on a similar framework to state and national plans. Pandemic planning at the local level will be assisted by the appointment of eighteen biopreparedness officers and epidemiologists in 2006, enabled by the provision of additional funds by the NSW Government.

\section{WHOLE-OF-GOVERNMENT PANDEMIC INFLUENZA PLANS}

During the period that national and many jurisdictional health sector pandemic plans were being formulated and released in 2005-2006, there was a growing realisation that pandemic planning and response was not only a responsibility of the health sector but, rather, required a whole-of-government input. In response, at the national level, the Coalition of Australian Governments Working Group on Influenza Pandemic Prevention and Preparedness was formed and charged with preparing the Australian Action Plan for Human Influenza Pandemic. This was released in July 2006. ${ }^{9}$ In November 2005, the NSW Premier established the NSW Influenza Pandemic Taskforce, comprising 22 state government agencies, to oversee state whole-of-government planning. The Taskforce released the NSW Human Influenza Pandemic Plan in August $2006^{10}$. This plan describes the governance arrangements that will be put in place during a pandemic, including the arrangements between the health sector and other NSW government agencies, and those between the NSW and Australian governments. It is a high-level strategic plan with operational detail to be included in supporting plans developed over subsequent months by various working groups. The focus of these working groups will be on the key areas of community management, workforce, body storage and disposal, border and quarantine, public information, information technology, continuity of the food-chain, and animal welfare.

\section{WHERE TO FROM HERE?}

During the past decade or so, the world has been confronted with a number of large-scale infectious diseases threatsthe spectre of bioterrorism in the late 1990s, the emergence of SARS in 2003, and the fear of a possible influenza pandemic fuelled by the appearance and rapid spread to three continents of $\mathrm{H} 5 \mathrm{~N} 1$ avian influenza in wild and domestic birds. In response, significant resources have been devoted to preparing for infectious disease emergencies, and some governments have established dedicated units to oversee this preparedness activity, for example the Australian Government's Office for Health Protection, and the Biopreparedness Unit within NSW Health's Division of Population Health.

Biopreparedness efforts around Australia are currently concentrated on preparing for pandemic influenza, and this is likely to continue for the foreseeable future as a great deal of work remains to be done at all levels of government, in the health and non-health sectors, and in private enterprise. However, the emphasis may switch to planning for other threats depending on whether the balance of risk is perceived to shift to other biological threats.

There is, of course, an opportunity cost in tying up valuable human and material resources in preparing for an influenza pandemic. The balance that governments and business must strike in this regard is made difficult by virtue of the uncertain timing and severity of the next pandemic. Planning for a possible H5N1 influenza pandemic will not be in vain should $\mathrm{H} 5 \mathrm{~N} 1$ not result in a pandemic. It is inevitable that an influenza pandemic will occur at some stage in the future and the current Australia-wide planning activity will hold this country in good stead to counter the threat posed by such an event. Also, because of the many crossovers in the planning for pandemic influenza and other large-scale infectious disease emergencies, pandemic planning will be of great benefit to Australia in meeting the challenge posed by future emerging, re-emerging, or deliberately emerging infectious diseases.

\section{REFERENCES}

1. Morens DM, Folkers GK, Fauci AS. The challenge of emerging and re-emerging infectious diseases. Nature 2004;430: 242-9.

2. World Health Organization. Avian influenza: assessing the pandemic threat. 2005. Available at: www.who.int/csr/ disease/influenza/WHO_CDS_2005_29/en/, accessed 15 September 2006.

3. World Health Organization. Summary of probable SARS cases with onset of illness from 1 November 2002 to 31 July 2003. Available at: www.who.int/csr/sars/country/table2004_04_21/ en/index.html, accessed 15 September 2006.

4. Taubenberger JK, Reid AH, Lourens RM, Wang R, Jin G, Fanning TG. Characterisation of the 1918 influenza virus polymerase genes. Nature 2005; 437:889-93.

5. World Health Organization. WHO global influenza preparedness plan. 2005. Available at: www.who.int/csr/ 
resources/publications/influenza/WHO_CDS_CSR_GIP 2005_5/en/, accessed 15 September 2006.

6. Commonwealth of Australia. Australian health management plan for pandemic influenza. 2006. Available at: www.health. gov.au/internet/wcms/publishing.nsf/Content/ohp-pandemicahmppi.htm, accessed 15 September 2006.

7. Commonwealth of Australia. Australian management plan for pandemic influenza. 2005.
8. NSW Health. NSW Health interim influenza pandemic action plan. 2005. Available at: www.health.nsw.gov.au/pubs/2005/ pdf/pandemic_ap.pdf, accessed 15 September 2006.

9. Commonwealth of Australia. National action plan for human influenza pandemic. 2006. Available at: www.dpmc.gov.au/ publications/pandemic/index.htm, accessed 15 September 2006.

10. NSW Government. New South Wales interim human influenza pandemic plan. Available at: www.health.nsw. gov.au/pandemic/docs/nswplan.pdf, accessed 15 September 2006. 곻

\section{PANDEMIC PLANNING AT THE COAL FACE: RESPONSIBILITIES OF THE PUBLIC HEALTH UNIT}

\author{
Keith Eastwood, Peter Massey and David Durrheim \\ Hunter New England Population Health \\ Hunter New England Area Health Service
}

\section{ABSTRACT}

Responding to an infectious disease pandemic requires a coordinated approach from all essential services. Public health units across NSW will play an important role in a range of control activities. These include: surveillance, education, communication, case ascertainment, case management (excluding clinical management), infection control, contact tracing, monitoring contacts in home quarantine, surveillance at borders, epidemiological studies and immunisation. Public health units are currently planning for such an emergency and these plans will need to be tested and refined under simulated conditions.
\end{abstract}

A well functioning disease surveillance system is necessary to ensure that the first cases of pandemic influenza are rapidly identified. Following this, control strategies will be implemented to retard the transmission of the virus while a vaccine is being developed. Surveillance will also detect the last case, signifying an end to the crisis. In between these two watershed surveillance events, public health units will play a pivotal role in responding to a pandemic. The purpose of this paper is to describe this role.

\section{INTERNATIONAL, AUSTRALIAN AND NSW PLANS FOR A PANDEMIC}

The World Health Organization has vigorously advocated global readiness for an influenza pandemic and planning by individual nations. ${ }^{1}$ The Australian Government has adopted an inclusive process of policy-making with states and territories. Some of the strategies and plans developed by the Australian Government Department of Health and Ageing are described in the contribution by the Chief Medical Officer in this issue of the Bulletin.

For emergencies occurring in NSW, coordination of the response is governed by the State Emergency and Rescue
Management Act, with the NSW Department of Health legislated to serve as the lead agency in responding to infectious disease emergencies. As all of society will be affected by a pandemic, the NSW Premier's Department is overseeing the involvement of other government departments and agencies in NSW.

Area health services across NSW will play a front-line role in providing clinical care in the event of a pandemic and ensuring appropriate local public health and mental health responses. Once the first few cases of pandemic influenza are identified, emergency departments will be placed on heightened alert to identify suspected pandemic cases. Dedicated influenza clinics will be opened when humanto-human spread has occurred within Australia. These clinics will manage all patients with symptoms suggestive of influenza to reduce the risk of infection to patients attending hospital for other reasons. Fever hospitals and staging facilities are planned for the clinical management of cases when existing acute care facilities are likely to be overwhelmed.

Since 2003, the World Health Organization has been monitoring the status of the avian influenza H5N1 strain that has caused deaths in people who have been in close contact with infected poultry. ${ }^{2}$ It is fair to say that this concern has accelerated global pandemic preparedness.

\section{THE ROLE OF THE PUBLIC HEALTH UNIT}

Public health units will have a number of vital roles during a pandemic, including: surveillance, education, communication, case ascertainment, case management (but not clinical management), infection control, contact tracing, monitoring contacts in home quarantine, surveillance at borders, epidemiological studies and immunisation. While these duties are not foreign to public health units, the potential number of cases and urgency of response, and the need to maintain large databases, makes pandemic influenza a particular challenge. The full scope of implementation of certain of these activities is yet to be determined and the responsibility for delivery may be shared with other 